\title{
Factors Associated with Oral Health Status in American Indian Children
}

\author{
Tamanna Tiwari • David O. Quissell • \\ William G. Henderson • Jacob F. Thomas • \\ Lucinda L. Bryant • Patricia A. Braun • Judith E. Albino
}

Received: 6 January 2014 /Revised: 27 February 2014 / Accepted: 16 April 2014 / Published online: 13 May 2014

(C) W. Montague Cobb-NMA Health Institute 2014

\begin{abstract}
The literature reports psychosocial, environmental, and cultural factors related to early childhood caries (ECC), but few studies have included American Indian/Alaska Native (AI/AN) populations. AI/AN children have the highest prevalence of ECC among any population group in the USA. This study examined sociodemographic characteristics of children and their parents/caregivers and psychosocial characteristics of parents/caregivers as risk factors for baseline oral health status of preschool children in the Navajo Nation, as part of a 3-year cluster randomized clinical trial to evaluate the effectiveness of trained community workers providing a fluoride varnish and oral health promotion intervention to. The study recruited 1,015 children at 52 Head Start Centers. Baseline ECC data were collected by calibrated dental hygienists for 981 of the children ages of 3-5 years, and a Basic Research
\end{abstract}

T. Tiwari $(\bowtie) \cdot$ J. F. Thomas $\cdot$ J. E. Albino

Centers for American Indian and Alaska Native Health, Colorado

School of Public Health, University of Colorado Anschutz Medical

Campus, Aurora, CO, USA

e-mail: tamanna.tiwari@ucdenver.edu

D. O. Quissell

Department of Craniofacial Biology, School of Dental Medicine, University of Colorado Anschutz Medical Campus,

Aurora, CO, USA

W. G. Henderson

Department of Biostatistics \& Informatics, Colorado School of Public Health, University of Colorado Anschutz Medical Campus, Aurora, CO, USA

L. L. Bryant

Department of Community and Behavioral Health, Colorado School of Public Health, University of Colorado Anschutz Medical Campus, Aurora, CO, USA

P. A. Braun

Children's Outcomes Research Program, University of Colorado

Anschutz Medical Campus, Aurora, CO, USA
Factors Questionnaire (BRFQ) was completed by their parents/caregivers. Bivariable analysis revealed that $\mathrm{dmfs}$ was higher in older children; in males; in children with male parents/caregivers; and when the parent/caregiver had less education and income, worse oral health behavior in caring for their children's teeth, and higher scores for external powerful others and external chance locus of control, greater perceived susceptibility and barriers, and lower scores for community risky behavior. In a multiple linear regression model, the variables that remained statistically significant were child's age and gender and oral health behavior score of the parent/caregiver. Intervening to improve parent/ caregiver oral health behavior in caring for the teeth of children potentially could in AI/AN children.

Keywords ECC - American Indian/Alaska Native children - Caries risk factors - Oral health behavior . Psychosocial factors

\section{Introduction}

Early childhood caries (ECC, or dental caries in young children) is defined as dental caries in the primary teeth of children younger than 6 years of age [1]. The rates of ECC are highest among low socioeconomic groups and indigenous and ethnic minorities $[2,3]$. ECC is associated with significant adverse physical, functional, and behavioral consequences [4] and also is believed to reflect caregiver practices and beliefs related to oral health [5].

Among US population groups, ECC prevalence is most extreme in American Indian/Alaska Native (AI/AN) children, suggesting disparate risk and the need for effective, culturally acceptable interventions [6-8]. The most recent Indian Health Service (IHS) report concerning AI/AN preschool children estimates prevalence of dental caries at $68.4 \%$, prevalence 
of untreated dental decay at $43.6 \%$, and a mean decayed, missing, and filled teeth $(\mathrm{dmft})$ measure three times greater than for non-Natives [6]. Dental caries among preschool children in Navajo Nation is especially severe; a recent survey reported a mean dmft of 6.5 for 2-5-year olds [6], the highest reported in any American Indian or other population group. Several risk factors have been identified for the development and progression of ECC. In a systematic review, [9] Harris et.al found 106 risk factors related to incidence of dental caries that included sociodemographic, dietary, and oral hygiene variables, feeding practices, and oral bacteria. Another recent review studied risk factors for ECC during the first year of life, and feeding practices, maternal circumstances, and oral health behaviors emerged as key risk factors [10]. Many researchers have studied risk factors other than diet and behavior; they identified maternal psychosocial factors including, stress, health beliefs, and cultural factors associated with ECC [2, $5,11]$.

Socioeconomic status (SES) of the parent has been associated with child's oral health status [4, 12-16], and the link persists even after controlling for other characteristics [17]. Maternal factors like mother's education, less positive attitudes, and oral health beliefs have been associated with dental caries in the primary dentition and with dental health services utilization $[2,4,17,18]$. Factors related to maternal health beliefs and oral health behaviors may vary with different SES and education levels [18]. Parents/caregiver's fatalistic oral health beliefs and religiosity were significantly associated with ECC in a study reported by Ismail et al. [5]. Mother's locus of control orientation (LOC) also has been associated with the oral health of the child; children of parents who have a higher external locus of control have greater dental caries experience [19]. Parental stress also has been associated with ECC [14] and may represent a larger constellation of factors such as low SES, educational level, and number of children in the family $[2,20]$. Though not much literature is available that describes factors associated with oral health of $\mathrm{AI} / \mathrm{AN}$ children; literature describing the risk factors associated with ECC in Canadian and Australian Aboriginal children include low SES of the parent, limited parent/caregiver oral health knowledge, and suboptimal oral health behaviors such as frequent consumption of sugary foods and drinks [21, 22].

There is a growing recognition of the need to understand how social, cultural, environmental, and psychological forces in the family affect oral health outcomes of children in the early years of life. The purpose of this article is to examine sociodemographic and psychosocial characteristics of parents/ caregivers as factors related to baseline oral health status of their children in a high-risk American Indian population from the Navajo Nation. The data were collected as part of the baseline assessment of Head Start children and their parents/ caregivers, as part of a 3-year cluster randomized clinical trial to evaluate the effectiveness of trained community workers providing a fluoride varnish and oral health promotion intervention to control the development of cavities.

\section{Methods}

\section{Study Design and Sample}

In 2008, the Center for Native Oral Health Research (CNOHR) at the University of Colorado Denver Anschutz Medical Center was funded to conduct a clinical trial in Navajo Nation Head Start Centers to evaluate the effects of an intervention to prevent ECC (Clinicaltrials.gov NCT01116739). We have used the term "prevention" although we are working with 3-5-year-old children in whom the disease process generally is already established. The intent of the intervention was prevention in the sense of limiting the increase, or rate of increase, of ECC.

Using a cluster design, researchers randomly assigned Head Start Centers (HSC) to intervention and usual care control conditions. The intervention consisted of the delivery of fluoride varnish (FV) to Head Start (HS) children, along with oral health promotion (OHP) activities and events separately for the children and their parents/caregivers; the intervention was unique in that it was provided by tribal members who had been trained in the basics of oral health and in the activities involved. The interventions were delivered over a 2year period. The primary outcome variable is decayed, missing, and filled tooth surfaces ( $\mathrm{dmfs}$ ) measured at baseline and then annually thereafter for 3 years. The parents/caregivers also completed a Basic Research Factors Questionnaire (BRFQ) at these same time points [23].

The sample size to attain sufficient statistical power was estimated at 1,040 HS children and their parents/ caregivers in $52 \mathrm{HS}$ classrooms, evenly divided between intervention and usual care control groups. Eligible participants included children ages 3-5 at enrollment into the study and a parent or other adult primary caregiver (henceforth referred to as caregiver) for each child. All the adult participants were compensated for their time. Children were American Indian, as defined by the tribe, or children of other race/ethnic groups who were enrolled in the HS classes. Children younger than age 3, those without an available consenting adult, and adults unable to understand English were excluded. Children were also excluded if they presented with an allergy to any components of the FV or had oral health conditions such as ulcerative gingivitis or stomatitis. This study was approved by the Navajo Nation Human Research Review Board, governing bodies at tribal and local levels, the tribal departments of HS and Education; HS parent councils, and the University of Colorado Multiple Institutional Review Board. 


\section{Data Collection}

\section{Decayed, Missing, and Filled Tooth Surfaces (dmfs) Measure}

Study-trained and calibrated licensed dental hygienists (examiners) blinded to the study condition conducted visual screenings of the enrolled children's mouths at baseline to determine dmfs using the method described by Pitts [24]. Trained data recorders entered the dmfs findings into an electronic dental research record called CARIN [25]. Prior to study initiation and annually thereafter, the dental examiners and data recorders were calibrated to a "gold standard" dentist to ensure they were able to collect data consistently and reliably during the study. The calibration training events consisted of conducting multiple dental examinations of the same children with different examiners to measure the degree of agreement among examiners. Kappa statistics were computed, and each examiner was required to meet a standard established in the protocol.

\section{Basic Research Factors Questionnaire BRFQ Variable} Construct

The BRFQ, a computerized 190-item questionnaire for caregivers, assesses their dental knowledge, attitudes, behaviors, and other psychosocial measures. The BRFQ collects data on a number of potential risk factors, including caregiver and household characteristics, caregiver and child's sociodemographics, caregiver oral health knowledge, oral health attitudes and oral health behaviors in caring for their children's teeth, caregiver resources, barriers, health status and dental care utilization; psychosocial scales, and child oral health status/quality of life. Table 1 presents the psychosocial and other measures used in the BRFQ, including subscales, descriptions, and ranges of the values. The BRFQ was designed to be administered using an audio computer-assisted self-interviewing (ACASI) system. Participants entered responses to survey items through mouse and keyboard input. Survey development was a collaborative effort involving three Oral Health Disparities Centers funded by the National Institute of Dental and Craniofacial Research (NIDCR). A crosscenter workgroup comprising investigators from NIDCRfunded Oral Health Disparities Centers at the University of Colorado Anschutz Medical Center, Boston University and the University of California San Francisco compiled the survey.

\section{Statistical Methods}

In bivariable analyses of categorical predictor variables, means and standard deviations are reported for $\mathrm{dmfs}$ in Navajo Head Start students for each category. To account for the clustering of children within HS classrooms, $p$ values are calculated from bivariable mixed-effect analyses where classrooms are treated as a random effect, indicating if there is a statistically significant difference in mean $\mathrm{dmfs}$ between categories. For continuous predictor variables, Pearson correlations between $\mathrm{dmfs}$ and the continuous predictor variable are reported, with a $p$ value for the test of whether the correlation coefficient is statistically significantly different from zero.

A multiple linear regression mixed-effects analysis was used to assess the simultaneous, independent association between each variable and dmfs. HS classrooms were treated as a random effect. Variables were included in this full model only if they achieved a significance level of $p \leq 0.20$ in bivariable analyses. In our sample, there was only a small proportion $(10.7 \%)$ of children with dmfs scores equal to zero, and the distribution of dmfs was only slightly skewed to the right. Consequently, we treated $\mathrm{dmfs}$ as a continuous, normally distributed variable in our analyses due to our relatively large sample size and protection against non-normality from the central limit theorem. All analyses were conducted in SAS version 9.3.

\section{Results}

A total of 1,015 children from 52 HS classrooms were recruited into the study. At baseline, the dmfs data were collected for 981 children, 488 males and 493 females. Most of the children $(97.4 \%)$ were ages 3 or 4 . The mean age of the caregivers was 31.9 years $(\mathrm{sd}=9.3)$, and $83.7 \%$ were female.

Table 2 presents mean $\mathrm{dmfs}$ for the categorical variables. Child's age and gender and caregiver's gender, education, and income were significantly related to $\mathrm{dmfs}(p<.05)$. Mean dmfs ranged from 18.23 for children at age 3 to 37.52 for children at age $5(p<0.0001)$. The mean $\mathrm{dmfs}$ score was higher in male than in female children ( 23.27 vs. $19.42, p=0.0035)$ and higher in children with a male vs. a female caregiver (24.37 vs. $20.75, p=0.032$ ). The children's mean dmfs was also higher if their caregiver reported less education $(p=0.0082)$ and income $(p=0.0014)$, although the association between higher income and lower mean dmfs was not monotonic. Mean dmfs level was not statistically significantly related to caregiver's employment status, whether they had access to a working vehicle, health of the caregiver's teeth and gums, or presence of caregiver comorbidities, alcohol use, social support, or financial stability.

Table 3 presents Pearson correlation coefficients between child's dmfs and the continuous variables. In general, the correlations were small in magnitude, but some were statistically significantly different from zero. Children's dmfs tended to increase with a lower caregiver oral health behavior score ( $r=-0.129, p<0.0001)$, increased external others and chance locus of control scores $(r=0.070, p=0.028$; and $r=0.087, p=$ 0.007), increased scores for two Health Belief Model 
Table 1 Explanation of measures in the Basic Research Facts Questionnaire (BRFQ)

Measure Description

Range (indicates the range of the computed scale/subscale)

Oral health locus of control

Three subscales

Internal locus of control (3)

External locus of control-

powerful others (3)

External locus of control-chance (3)

\author{
Health Belief Model \\ Four subscales \\ Perceived susceptibility (3) \\ Perceived seriousness (3) \\ Perceived barriers (5) \\ Perceived benefits (5)
}

Self-efficacy (14)

Importance (14)

Sense of coherence

Three subscales, and overall score

Comprehensibility (5)

Meaningfulness (4)

Manageability (4)

Overall sense of coherence (13)

Distress (6)

Chronic stress

Five subscales

Expectations (3)

Location hassles (5)

Community family dysfunction (2)

Community risky behaviors (5)

Community economic distress (2)

Perceived discrimination (9)

Oral health behavior (9)

Oral health knowledge (14)

Alcohol use (3)

Social support (4)

Financial stability (4)
Locus of control (LOC) measure captures a person's attitudes about who or what has control over their child's oral health outcomes (i.e., the parent themselves, other people, or chance)

Each subscale represents the average score for all items within the subscale and represents the extent to which participants believes control for their child's oral health outcomes lies with the parent (internal LOC), the dentist (powerful other LOC), or is up to chance (chance LOC)

The Health Belief Model is one of the major models intended to explain health behavior. The model predicts that behavior is a function of the subscales

Perceived susceptibility - how susceptible does a parent feel his/her child is to poor oral health outcomes?

Perceived severity - how severe does the parent think developing caries would be?

Perceived barriers - does the parent perceive many barriers to following recommended oral health behavior?

Perceived benefits - does the parent perceive many benefits to following recommended oral health behavior?

Self-efficacy represents a person's confidence that he/she can successfully engage in a specific health behavior. The overall self-efficacy score represents how sure participants are that they can engage in recommended behavior to take care of their children's teeth

The overall importance score represents how important it is to participants that they engage in specific oral health behaviors (the same behaviors as mentioned above, for self-efficacy)

Sense of coherence (SOC) is a construct intended to assess the degree to which participants feel the world makes sense and has meaning

The overall distress score represents the amount of distress participants have experienced in the last 30 days

Chronic stress captured ongoing stress related to personal expectations, hassles associated with the local community, and community dysfunction

The perceived discrimination measure represents the amount of discrimination participants feel they are subject to, on account of being American Indian

The overall behavior score represents the percentage of oral health behavior items that were answered with an "adherent" response. Adherent means the participant is following the recommended oral health behavior

The overall knowledge score represents the percentage of oral health knowledge items answered correctly

A shortened version of the Alcohol Use Disorders Identification Test (AUDIT). Because the shortened version includes only the three consumption items, it is referred to as the AUDIT-C. The alcohol score provides an indication of the degree to which a participant drinks excessively

The social support score represents the average score for items within the instrumental social support section of the oral health survey. This overall score indicates the degree to which participants believe they have others available to help them when needed

The financial stability score is a measure of the degree to which participants feel they have adequate access to the basic things people need, such as food and clothing
$1-5$

$1=$ Strongly disagree

$5=$ Strongly agree

1-5

$1=$ Strongly disagree

$5=$ Strongly agree

\section{1-5}

$1=$ Not sure at all

$5=$ Extremely sure

1-5

$1=$ Not at all important

$5=$ Extremely important

1-7

Higher numbers indicate stronger coherence

1-5

$1=$ None of the time

$5=$ All the time

$1-4$

$1=$ Strongly disagree

$4=$ Strongly agree

1-4

$1=$ Never

$4=$ Often

$0-100 \%$

0-100\%

0-12

Large numbers represent greater alcohol use

$0-1$

$0=$ No available support

$1=$ Support available

0-1

$0=$ Financially unstable

$1=$ Financially stable

In the first column, numbers in parentheses represent the number of items in the scale/subscale 
Table 2 Bivariable relationship between $\mathrm{dmfs}$ and categorical variables

\begin{tabular}{|c|c|c|c|c|}
\hline & \multirow[t]{2}{*}{ Number } & \multicolumn{2}{|l|}{$\mathrm{dmfs}$} & \multirow[t]{2}{*}{$P$ value } \\
\hline & & Mean & Standard deviation & \\
\hline Child age & & & & $<0.0001$ \\
\hline 3 & 408 & 18.23 & 19.35 & \\
\hline 4 & 546 & 22.86 & 19.79 & \\
\hline 5 & 25 & 37.52 & 22.98 & \\
\hline Child's gender & & & & 0.0035 \\
\hline Male & 488 & 23.27 & 20.46 & \\
\hline Female & 493 & 19.42 & 19.34 & \\
\hline Gender (parent) & & & & 0.032 \\
\hline Male & 159 & 24.37 & 21.65 & \\
\hline Female & 822 & 20.75 & 19.61 & \\
\hline Education & & & & 0.0082 \\
\hline Less than HS grad & 153 & 22.98 & 19.00 & \\
\hline HS grad/GED & 364 & 23.50 & 21.29 & \\
\hline Some college/vocational & 340 & 19.85 & 18.96 & \\
\hline College degree or more & 112 & 16.83 & 17.67 & \\
\hline Income & & & & 0.0014 \\
\hline refused, don't know, missing & 153 & 19.68 & 18.83 & \\
\hline Less than $\$ 10 \mathrm{k}$ & 411 & 23.97 & 21.05 & \\
\hline$\$ 10 \mathrm{k}$ to $<\$ 20 \mathrm{k}$ & 169 & 22.01 & 19.65 & \\
\hline$\$ 20 \mathrm{k}$ to $<\$ 30 \mathrm{k}$ & 90 & 14.98 & 16.93 & \\
\hline$\$ 30 \mathrm{k}$ to $<\$ 40 \mathrm{k}$ & 68 & 17.28 & 17.9 & \\
\hline Greater than or equal to $\$ 40 \mathrm{k}$ & 90 & 20.27 & 20.06 & \\
\hline Employment & & & & 0.097 \\
\hline Employed (full time or part time) & 275 & 19.93 & 19.91 & \\
\hline Not employed & 678 & 22.22 & 20.12 & \\
\hline Do you have access to a working vehicle? & & & & 0.23 \\
\hline No & 120 & 23.42 & 20.29 & \\
\hline Yes & 847 & 21.06 & 19.91 & \\
\hline $\begin{array}{l}\text { In general, how would you describe the } \\
\text { health of your own teeth and gums? }\end{array}$ & & & & 0.92 \\
\hline Excellent & 46 & 23.09 & 24.97 & \\
\hline Very good & 135 & 20.70 & 20.45 & \\
\hline Good & 382 & 20.78 & 19.59 & \\
\hline Fair & 310 & 21.89 & 19.57 & \\
\hline Poor & 80 & 20.65 & 19.65 & \\
\hline Number of comorbidities & & & & 0.94 \\
\hline 0 & 655 & 21.46 & 20.11 & \\
\hline 1 & 216 & 21.53 & 20.37 & \\
\hline 2 or more & 103 & 20.72 & 18.59 & \\
\hline Alcohol use, total score equals 1 or higher & & & & 0.76 \\
\hline No & 686 & 21.56 & 19.79 & \\
\hline Yes & 263 & 21.09 & 20.59 & \\
\hline Social support, overall score equals 1 & & & & 0.48 \\
\hline No & 436 & 21.91 & 19.47 & \\
\hline Yes & 531 & 20.91 & 20.45 & \\
\hline Financial stability, overall score equals 1 & & & & 0.51 \\
\hline No & 265 & 20.63 & 18.73 & \\
\hline Yes & 704 & 21.66 & 20.42 & \\
\hline
\end{tabular}


Table 3 Bivariable relationship between dmfs and continuous variables

\begin{tabular}{|c|c|c|}
\hline & Correlation & $P$ value \\
\hline \multicolumn{3}{|l|}{ Sociodemographics } \\
\hline Parent age & -0.053 & 0.098 \\
\hline Total number of household members & -0.024 & 0.453 \\
\hline \multicolumn{3}{|l|}{ Behavior } \\
\hline Overall score & -0.129 & $<0.0001$ \\
\hline \multicolumn{3}{|l|}{ Knowledge } \\
\hline Overall score & 0.014 & 0.672 \\
\hline \multicolumn{3}{|l|}{ Psychosocial measures } \\
\hline \multicolumn{3}{|l|}{ Oral health locus of control (three subscales) } \\
\hline Internal & -0.040 & 0.211 \\
\hline External powerful others & 0.070 & 0.028 \\
\hline External chance & 0.087 & 0.007 \\
\hline \multicolumn{3}{|l|}{ Health Belief Model (four subscales) } \\
\hline Perceived susceptibility & 0.097 & 0.002 \\
\hline Perceived seriousness & -0.018 & 0.570 \\
\hline Perceived barriers & 0.093 & 0.004 \\
\hline Perceived benefits & -0.017 & 0.591 \\
\hline Self-Efficacy (overall score) & -0.050 & 0.116 \\
\hline Importance (overall score) & 0.017 & 0.605 \\
\hline \multicolumn{3}{|c|}{ Sense of coherence (three subscales, and an overall score) } \\
\hline Comprehensibility & -0.045 & 0.161 \\
\hline Manageability & -0.021 & 0.515 \\
\hline Meaningfulness & -0.046 & 0.153 \\
\hline Overall score & -0.043 & 0.182 \\
\hline Distress (overall score) & -0.007 & 0.829 \\
\hline \multicolumn{3}{|l|}{ Stress (five subscales) } \\
\hline Expectations & 0.035 & 0.273 \\
\hline Location hassles & 0.012 & 0.714 \\
\hline Community family dysfunction & -0.040 & 0.216 \\
\hline Community risky behavior & -0.064 & 0.049 \\
\hline Community economic distress & -0.015 & 0.646 \\
\hline Perceived discrimination (overall score) & -0.049 & 0.126 \\
\hline \multicolumn{3}{|l|}{ Health literacy } \\
\hline Overall score & -0.013 & 0.686 \\
\hline
\end{tabular}

Measured by Pearson correlation coefficients

constructs, perceived susceptibility $(r=0.097, p=0.002)$ and perceived barriers $(r=0.093, p=0.004)$, and a decreased score for community risky behavior $(r=-0.064, p=0.049)$. When all of the potential variables with a bivariable association with $\mathrm{dmfs}$ of $p \leq 0.20$ were entered simultaneously into a multivariable regression model, only three variables had significant associations with the child's baseline dmfs measure - child age, child gender, and overall oral health behavior score of the caregiver (Table 4). Dmfs was greater with increasing child age, lower in females, and lower with higher oral health behavior score. The total variance of $\mathrm{dmfs}$ explained by the regression equation was only $6 \%$.

We explored whether the lack of statistical significance for many of the 17 independent variables in Table 4 was due to high correlations among the variables. Only two pairs of the 17 variables (locus of control due to chance and other, and sense of coherence-meaningfulness and comprehensibility) had correlations $\geq 0.50$, and when one variable was removed from each pair and the analysis redone, the results did not change. We also performed multiple linear regression analyses with $\mathrm{dmfs}$ as the dependent variable and each individual psychosocial measure as the independent variable along with the sociodemographic variables as covariates. In these analyses, there were only two psychosocial variables that became statistically significant (perceived susceptibility and barriers from the Health Belief Model). On the basis of these analyses, we concluded that high correlations among the 17 independent variables were not a strong reason for the negative results found for many of the variables in Table 4.

\section{Discussion}

In bivariable analyses using our baseline data for 981 American Indian children, we found that dmfs was higher in older children; in males; in children with male caregivers; when the caregiver had less education and income; when caregivers had worse self-reported scores for oral health behavior in caring for the children's teeth, higher scores for external powerful others and external chance locus of control, higher scores for perceived susceptibility and barriers, and lower scores for community risky behavior. All of these findings tend to be in the direction expected, with the possible exception of the community risky behavior scale. When all variables were simultaneously included in a multiple linear regression model, the only variables that remained statistically significant were child's age, gender, and oral health behavior score of the caregiver. This indicates that these variables tend to have much stronger associations with baseline dmfs than do most of the psychosocial measures.

Although the regression model accounts for only $6 \%$ of the variance in baseline dmfs, it and the bivariable analyses provide insight into factors likely associated with dental caries specific to the AI population. These baseline results suggest the need for further examination, which the longitudinal continuation of this study may provide.

Parental scores on locus of control (LOC) including three subscales (internal LOC, external LOC powerful other, and external LOC chance control) were measured, and powerful others and chance control of health outcomes were related to children's dmfs scores. This suggests that these parents believed there was little they could do to influence their 
Table 4 Model of the association between participant characteristics and dmfs
Full model mixed-effects multivariable linear regression analysis with dmfs as the dependent variable and the independent variables $(N=921$, adjusted $R$-squared $=0.06$ )

\begin{tabular}{|c|c|c|c|}
\hline Descriptive characteristic & Model estimate & SE & $P$ value \\
\hline \multicolumn{4}{|l|}{ Sociodemographics } \\
\hline Child age & & & $<0.0001$ \\
\hline Age 3 vs. 5 & -19.33 & 4.38 & \\
\hline Age 4 vs. 5 & -15.21 & 4.35 & \\
\hline Child gender (female vs. male) & -3.42 & 1.29 & 0.01 \\
\hline Parent age & -0.06 & 0.07 & 0.42 \\
\hline Parent gender (female vs. male) & -2.48 & 1.82 & 0.17 \\
\hline Education & & & 0.21 \\
\hline College degree or more vs. less than HS grad & -1.74 & 2.65 & \\
\hline Some college/vocational vs. less than HS grad & -1.13 & 2.04 & \\
\hline HS grad/GED vs. less than HS grad & 1.90 & 1.94 & \\
\hline Income & & & 0.16 \\
\hline Refused, don't know, missing vs. less than $\$ 10 \mathrm{k}$ & -3.45 & 2.04 & \\
\hline Greater than or equal to $\$ 40 \mathrm{k}$ vs. less than $\$ 10 \mathrm{k}$ & -1.72 & 2.42 & \\
\hline$\$ 30 \mathrm{k}$ to $<\$ 40 \mathrm{k}$ vs. less than $\$ 10 \mathrm{k}$ & -3.41 & 2.69 & \\
\hline$\$ 20 \mathrm{k}$ to $<\$ 30 \mathrm{k}$ vs. less than $\$ 10 \mathrm{k}$ & -5.75 & 2.40 & \\
\hline$\$ 10 \mathrm{k}$ to $<\$ 20 \mathrm{k}$ vs. less than $\$ 10 \mathrm{k}$ & -0.89 & 1.88 & \\
\hline Employment (full or part time vs. not employed) & -2.20 & 1.47 & 0.13 \\
\hline \multicolumn{4}{|l|}{ Behavior } \\
\hline Overall score & -0.08 & 0.03 & 0.02 \\
\hline \multicolumn{4}{|l|}{ Psychosocial measures } \\
\hline \multicolumn{4}{|l|}{ Oral health locus of control (two subscales) } \\
\hline External others & -0.30 & 0.75 & 0.69 \\
\hline External chance & 0.90 & 0.74 & 0.22 \\
\hline \multicolumn{4}{|l|}{ Health Belief Model (two subscales) } \\
\hline Perceived susceptibility & 1.22 & 0.79 & 0.12 \\
\hline Perceived barriers & 0.18 & 1.11 & 0.87 \\
\hline Self-efficacy (overall score) & -0.36 & 1.35 & 0.79 \\
\hline \multicolumn{4}{|l|}{ Sense of coherence (two subscales) } \\
\hline Comprehensibility & -0.54 & 0.69 & 0.43 \\
\hline Meaningfulness & 0.17 & 0.71 & 0.81 \\
\hline \multicolumn{4}{|l|}{ Stress (one subscale) } \\
\hline Community risky behavior & -0.23 & 0.68 & 0.74 \\
\hline Perceived discrimination (overall score) & -2.12 & 1.25 & 0.09 \\
\hline
\end{tabular}

children's oral health and it was luck or chance that would decide the fate of their child's oral health. Parental external LOC has been associated with higher untreated dental caries and loss to follow up in preschool children [19, 26].

Although not significant in the multiple linear regression analysis, caregiver perceptions on two subscales of the Health Belief Model, perceived susceptibility and perceived barriers, were associated with child's dmfs and seemed to fit this pattern of fatalistic beliefs. Children of caregivers who perceived barriers to regular dental checkups and brushing their child's teeth at night and thought fluoride varnish applications were inconvenient had higher dmfs scores. Similarly, caregivers with perceived susceptibility thought that it is normal for children to develop dental caries and that oral health was not as important as general health.

It is noted that four of these caregiver belief variables (caregivers' external powerful other and external chance LOC, community risky behavior, and the perceived barrier subscale of the Health Belief Model) were significantly associated with reported caregiver income and education $(p<.0001)$. Higher caregiver education and income were inversely related to these variables (except community risky behavior, which had a positive relationship), suggesting a strong effect of socioeconomic status on the attitudes and health beliefs of caregivers that are negatively associated with the oral health of their children. This is consistent with 
previous studies that have emphasized that maternal education influences beliefs and attitudes toward oral health of their children [2].

Male children had higher dmfs scores than female children in the study; this observed gender difference was also found in some other studies examining prevalence of dental caries in preschool children in First Nation communities in Canada [27], a cross-sectional study in Brazil [28] and another study studying different ethnic groups in Amsterdam [29]. None of the studies suggested any reason for the gender differences; however, it has been postulated that female adolescents consider oral appearance more important than males, and perhaps, this may be a motivating factor in younger children as well [30]. Also, adolescent girls scored favorably on oral health behaviors such as oral hygiene habits and showed more interest in oral health than boys [31], and it can be assumed that these behaviors start to develop early on. The longitudinal continuation of this study may provide more concrete answers to the gender differences in dental caries experiences in young children.

Child's age had the strongest association with baseline dental caries in children in this study; the mean dmfs was 18.23 at age $3,22.86$ at age 4 , and 37.52 at age 5 . This has been reported in studies of other populations as well [4, 32-34], but our data suggest that age may have a stronger relationship with ECC $(p<0.0001)$ in American Indian populations. Two explanations can be given for child's age to be strongly associated with dental caries. First, with increase in age, there are more teeth and tooth surfaces that are vulnerable to caries, and second, older children have had more time for the teeth to be exposed to cariogenic influences; both circumstances increase the quantitative risk of dental caries development. Early eruption patterns have been reported in American Indian children compared to other populations, and this might also lead to greater exposure associated with increased risk of ECC [35].

Caregiver oral health behavior toward their children had the third strongest association with dental caries in our data. Caregiver's oral health behavior was operationalized as the percentage of recommended behaviors that the caregiver engaged in on behalf of their children. Oral health behavior questions in this study were related to oral hygiene maintenance for the child, including frequency of tooth brushing, use of fluoridated tooth paste, supervision while tooth brushing, and frequency of consuming sugary foods and drinks. Our finding of an inverse relationship between caregivers' oral health behaviors with their children and baseline dmfs in children replicates similar findings in other studies. Several investigators $[16,32,36]$ have identified daily frequency of brushing and parental assistance in brushing as protective factors against dental caries development. Consumption of sugar and its amount, frequency, and timing also have been identified as critical factors in dental caries development [9]. Thus, a balance between the harmful effects of sugar consumption and oral hygiene maintenance is an important theme in prevention of dental caries in children. These findings suggest that oral health promotion activities with new parents/ caregivers could establish good oral health behaviors early in life and prevent dental caries from an early age in children.

Although not significant in the multiple linear regression analysis, caregiver income and education were significantly associated with dental caries in the bivariable analyses. The restricted range of incomes in our data may be relevant here; $41.8 \%$ of the study population had an annual income of $\$ 10,000$ or less. Nonetheless, even in this low-income population, relatively higher annual incomes appeared to be protective against ECC; when parents had annual incomes of less than $\$ 10,000$, their children had a mean dmfs of 23.97 , compared with 14.98 for children whose parents had annual incomes of $\$ 20,000$ to $<\$ 30,000(p=0.0014)$. These findings for the effects of relative income levels within a low-income population have been reported in other studies $[4,37]$.

In attempting to identify risk factors for ECC in an American Indian population with extremely high dental caries experience, we found that age and gender, along with caregiver's general levels of caries preventive behaviors on behalf of their children, were significantly associated with dental caries. Our observation of the relationships of certain other variables to ECC scores, albeit not predictive, may help us to understand these patterns of disease experience. Higher levels of education and income may provide experiences that are helpful to caregivers in learning what can be done to prevent caries in their children and also in developing attitudes and beliefs that are supportive of engaging in these behaviors. Understanding this complex of "upstream" or socio-environmental variables in the development of oral health disparities can be essential to developing interventions and approaches to prevention that eventually will lead to greater health equity among populations.

Acknowledgment The data for this study come from a clinical trial entitled "Preventing Caries in Preschoolers: Testing a Unique Service Delivery Model in American Indian Head Start Programs" (ClinicalTrials.gov NCT01116739), funded by the National Institute of Dental and Craniofacial Research (U54 DE019259-03 PI: Albino). We would like to thank the Navajo Nation as well as other participants who gave so graciously of their time and effort. The content is solely the responsibility of the authors and does not necessarily represent the official views of the National Institutes of Health. Basic Research Factors Questionnaire (BRFQ) developed with support from: U54DE019285, U54DE019275, and U54DE019259. CARIN software developed with support from: US DHHS/NIH/NIDCR U54DE014251 and R21DE018650.

Conflict of Interest Tiwari T, Quissell DO, Henderson WG, Thomas JF, Bryant LL, Braun PA, and Albino J declare that they have no conflict of interest.

Informed Consent All procedures followed were in accordance with the ethical standards of the responsible committee on human experimentation (institutional and national) and with the Helsinki Declaration of 1975, as revised in 2000 (5). Informed consent was obtained from all patients for being included in the study. 


\section{References}

1. American Academy of Pediatric Dentistry, American Academy of Pediatrics. Policy on early childhood caries (ECC): classifications, consequences, and preventive strategies. Pediatr Dent. 20082009;30:40-3.

2. Seow KW. Environmental, maternal, and child factors which contribute to early childhood caries: a unifying conceptual model. Int J Paediatr Dent. 2012;22:157-68.

3. Peterson PE. Socio-behavioral risk factors in dental caries - international perspectives. Community Dent Oral Epidemiol. 2005;33:274-9.

4. Finlayson TL, Siefert K, Ismail AI, Sohn W. Psychosocial factors and early childhood caries among low-income African-American children in Detroit. Community Dent Oral Epidemiol. 2007;35:439-48.

5. Ismail AI, Lim S, Sohn W, Willem JM. Determinants of early childhood caries in low-income African American young children. Pediatr Dent. 2008;30:289-96.

6. Phipps KR, Ricks TL, Manz MC, Blahut P. Prevalence and severity of dental caries among American Indian and Alaska Native preschool children. J Public Health Dent. 2012;72:208-15.

7. United States Department of Health and Human Services Centers for Disease Control. Dental caries in American Indian and Alaskan native children. MMWR Morbidity/Mortality Weekly Report. 1985;34:400-1.

8. Nash DA, Nagel RJ. Confronting oral health disparities among American Indian/Alaska Native children: the pediatric oral health therapist. Am J Public Health. 2005;95(8):1325-9.

9. Harris R, Nicoll AD, Adair PM, Pine CM. Risk factors for dental caries in young children: a systematic review of the literature. Community Dent Health. 2004;21:71-85.

10. Leong PM, Gussy MG, Barrow SYL, Silva-Sanigorski A, Waters E. A systematic review of risk factors during first year of life for early childhood caries. Int J Paediatr Dent. 2013;23:235-50.

11. Reisine S, Douglass JM. Psychosocial and behavioral issues in early childhood caries. Community Dent Oral Epidemiol. 1998;26:32-44.

12. Antunes JLF, Narvai PC, Nugent ZJ. Measuring inequalities in the distribution of dental caries. Community Dent Oral Epidemiol. 2004;32:41-8.

13. Crall JJ, Edelstein B, Tinanoff N. Relationship of microbiological, social, and environmental variables to caries status in young children. Pediatr Dent. 1990;12:233-6.

14. Tang C, Quinonez RB, Hallett K, Lee JY, Kenneth WJ. Examining the association between parenting stress and the development of early childhood caries. Community Dent Oral Epidemiol. 2005;33:454-60.

15. Reisine S, Litt M. Social and psychological theories and their use for dental practice. Int Dent J. 1993;43:279.

16. Hallett K, O'Rourke P. Social and behavioural determinants of early childhood caries. Aust Dent J. 2003;48:27-33.

17. Casanova-Rosado AJ, Medina-Solís CE, Casanova-Rosado JF, Vallejos-Sánchez AA, Maupomé G, Ávila-Burgos L. Dental caries and associated factors in Mexican schoolchildren aged 6-13 years. Acta Odontol Scand. 2005;63:245-51

18. Quinonez RB, Keels M, Vann Jr W, McIver F, Heller K, Whitt J. Early Childhood Caries: analysis of psychosocial and biological factors in a high-risk population. Caries Res. 2001;35: 376-83.

19. Chase I, Berkowitz R, Proskin H, Weinstein P, Billings R. Clinical outcomes for Early Childhood Caries (ECC): the influence of health locus of control. Eur J Paediatr Dent. 2004;5:76-80. http:// europepmc.org/abstract/MED/15198624.
20. Litt MD, Reisine S, Tinanoff N. Multidimensional causal model of dental caries development in low-income preschool children. Public Health Rep. 1995;110:607.

21. Jamieson LM, Armfield JM, Roberts-Thomson KF. Oral health inequalities among indigenous and nonindigenous children in the Northern Territory of Australia. Community Dent Oral Epidemiol. 2006;34:267-76.

22. Lawrance HP, Romanetz M, Rutherford L, Cappel L, Binguis D, Rogers JB. Oral health of Aboriginal preschool children in Northern Ontario. PROBE. 2004;38:174-90. http://www.caphd.ca/sites/ default/files/Aboriginal_Preschool.pdf.

23. Quissell D, Bryant LL, Braun P, Cudeii D, Johs N, Smith V, et al. Preventing caries in preschoolers: an innovative community-based clinical trial in Navajo Nation Head Start programs. Contemporary Clinical Trials. 2014;37:242-51.

24. Pitts NB. Clinical diagnosis of dental caries: a European perspective. J Dent Educ. 2001;65:972-8.

25. University of California San Francisco. CARIN (Caries Research Instrument). 1.4.8 ed. San Francisco, California 2010. Available from: http://techtransfer.universityofcalifornia.edu/NCD/19030.html

26. Lenčová E, Pikhart H, Broukal Z, Tsakos G. Relationship between parental locus of control and caries experience in preschool children - cross-sectional survey. BMC Public Health. 2008:8:208.

27. Peressini S, Leake JL, Mayhall JT, Maar M, Trudeau R. Prevalence of early childhood caries among First Nations children, District of Manitoulin, Ontario. Int J Paediatr Dent. 2004;14:101-10.

28. Maciel SM, Marcenes W, Watt RG, Sheiham A. The relationship between sweetness preference and dental caries in mother/child pairs from Maringa-Pr, Brazil. Int Dent J. 2001;51:83-8.

29. Verrips GH, Frencken JE, Kalsbeek H, ter Horst G, Filedt KokWeimar TL. Risk indicators and potential risk factors for caries in 5 -year-olds of different ethnic groups in Amsterdam. Community Dent Oral Epidemiol. 1992;20:256-60.

30. Poutanen R, Lahti S, Tolvanen M, Hausen H. Gender differences in child-related and parent-related determinants of oral health-related lifestyle among 11 to 12 year old Finnish School children. Acta Odont Scandinavia. 2007;65:194-200.

31. AL OÈ, Halling A, Lindblad U. Gender differences in knowledge, attitude, behavior and perceived oral health among adolescents. Acta Odontol Scand. 1999;57:231-6.

32. Vanobbergen J, Martens L, Lesaffre E, Bogaerts K, Declerck D. Assessing risk indicators for dental caries in the primary dentition. Community Dent Oral Epidemiol. 2001;29:424-34.

33. Schroth RJ, Cheba V. Determining the prevalence and risk factors for early childhood caries in a community dental health clinic. Pediatr Dent. 2007;29:387-96.

34. Barnes GP, Parker WA, Lyon Jr TC, Drum MA, Coleman GC. Ethnicity, location, age, and fluoridation factors in baby bottle tooth decay and caries prevalence of Head Start children. Public Health Rep. 1992;107:167-73.

35. Kramer KWO, Dawson DV, Warren JJ, Phipps K, Starr DE, Marshall TA, Drake DR. Eruption of deciduous teeth in American Indian Children: a historical comparison. National Oral Health Conference, 2012. http://www.nationaloralhealthconference.com/ docs/presentations/2012/05-01/Eruption\%20of\%20Deciduous $\%$ 20Teeth.pdf

36. Habibian M, Roberts G, Lawson M, Stevenson R, Harris S. Dietary habits and dental health over the first 18 months of life. Community Dent Oral Epidemiol. 2001;29:239-46.

37. Pattussi MP, Marcenes W, Croucher R, Sheiham A. Social deprivation, income inequality, social cohesion and dental caries in Brazilian school children. Soc Sci Med. 2001;53:915-25. 